\title{
Partner Uncertainty and the Dynamic Boundary of the Firm
}

\author{
By Thomas Hellmann and Veikko Thiele**
}

\begin{abstract}
We develop a new theory of the dynamic boundary of the firm where asset owners may want to change partners ex post. We identify a fundamental trade-off between ( $i$ ) a "displacement externality" under non-integration, where a partner leaves a relationship even though his benefit is worth less than the loss to the displaced partner, and (ii) a "retention externality" under integration, where a partner inefficiently retains the other. With more asset specificity, displacement externalities matter more and retention externalities less, so that integration becomes more attractive. Wealth can resolve ex post inefficient partner arrangements, but may weaken ex ante incentives for specific investments. (JEL D21, D23, D25, D62, D86, G31)
\end{abstract}

A central question in the theory of the firm is who should own the productive assets. It is commonly presumed that all asset owners know who their optimal trading partners are. In this paper, we introduce uncertainty about the optimal partner match. This uncertainty generates a dynamic trade-off between the commitment to a trading relationship (integration) versus the flexibility of seeking new relationships (non-integration). We ask how partner uncertainty affects the allocation of property rights over productive assets, and how it influences the subsequent evolution and performance of the firm.

We identify a novel trade-off between integration and non-integration that is based on the dynamics of partner changes. Non-integration gives parties the freedom to easily leave their partners, whereas integration gives parties the security that their partners cannot easily leave them. Each regime has its strengths and weaknesses. Under non-integration parties have the flexibility of leaving, but may also find themselves in a situation where the harm to the party left behind exceeds the benefit to the leaving party. We call this a displacement externality. Under integration no such inefficient leaving occurs, but partners may find themselves

\footnotetext{
* Hellmann: University of Oxford, Saïd Business School, Park End Street, Oxford OX1 1HP, United Kingdom (email: thomas.hellmann@sbs.ox.ac.uk); Thiele: Queen's University, Smith School of Business, Goodes Hall, 143 Union Street, Kingston, Ontario, K7L 3N6, Canada (email: thiele@queensu.ca). We would like to thank two anonymous referees, Philippe Aghion, Florian Ederer, Bob Gibbons, Trond Olsen, Barbara Spencer, Birger Wernerfelt, Ralph Winter, seminar participants at Texas A\&M University, Carnegie Mellon University, the University of British Columbia, the University of Toronto, and Drexel University, and participants of the European Meeting of the Econometric Society (ESEM) in Malaga, the Annual Meeting of the European Association for Research in Industrial Economics (EARIE) in Rome, and the Annual Conference of the Canadian Economics Association in Vancouver for valuable comments and suggestions.

Go to https://doi.org/10.1257/mic.20160016 to visit the article page for additional materials and author disclosure statement(s) or to comment in the online discussion forum.
} 
in the opposite situation. Partners may inefficiently stay together even though the individual value of leaving would exceed the joint value of staying together. We call this a retention externality.

We use a model set-up similar to Grossman and Hart (1986) where there are two owner-managers. They have inalienable human capital, as well as alienable co-specialized assets, which we can think of physical capital or intellectual property. We allow for team production with private efforts, so that the partners' profit sharing agreement affects their effort incentives. The optimal allocation of property rights either consists of integration with joint asset control, or non-integration where each partner retains control over his own asset. We first consider a simple model without specific investments. This shuts down the standard trade-off for the optimal asset ownership known from the property rights theory, and allows us to focus on the new determinants that emerge solely from partner uncertainty.

The optimal ex ante allocation of asset ownership depends on the degree of partner uncertainty, and the associated inefficiencies. Our base model shows that joint asset ownership is optimal when displacement externalities loom large, whereas individual asset ownership is preferred when retention externalities matter more. The relative importance of displacement and retention externalities depends on how good the original match between partners is. The greater the asset specificity, the greater the displacement externality, and also the smaller the retention externality. Higher asset specificity therefore favors joint asset ownership.

When allowing for relation-specific investments, we find that joint asset ownership always provides stronger incentives for specific investments. The key intuition is that joint asset ownership is efficient when the internal match is good, but can cause retention externalities when the internal match is poor. By contrast, individual asset ownership is efficient when the internal match is poor, but can cause displacement externalities when the internal match is good. Consequently, joint (individual) asset ownership increases (decreases) the difference between the good and the bad match, which is good (bad) for incentives.

We also find that having wealth is a double-edged sword. On the one hand, it enables transfer payments that mitigate ex post inefficiencies. On the other hand, it weakens ex ante incentives for specific investments, precisely because it allows partners to mitigate ex post inefficiencies when the partner match is poor.

The model generates testable predictions concerning the dynamics of firm boundaries and partner selection. The higher the quasi-rents for the initial partner match, the more desirable it is to integrate. This formalizes an argument associated with transaction cost theories (Williamson 1985). However, the model also predicts that the higher the expected quasi-rents in a potential match with an alternative partner, the less attractive it is to integrate upfront. This second prediction takes a new dynamic perspective, comparing current quasi-rents against potential future quasi-rents from alternative trading relationships. The model also generates an unambiguous prediction that integration leads to more specific investments. Finally, another important prediction is that integration is associated with greater partner stability. This stands out against the property rights literature (Grossman and Hart 1986) which typically assumes optimal partner matches, and therefore does not consider dynamic stability. 


\section{Related Literature}

Our model makes several departures from the seminal property rights models of Grossman, Hart, and Moore (erately excludes specific investments, which is the central mechanism for determining asset ownership in the GHM model. ${ }^{2}$ Second, our model allows for ex post inefficiencies, which do not occur in GHM. Third, in the GHM model switching to an outside partner is a threat that is never exercised in equilibrium, whereas in our model partner changes actually occur in equilibrium. For example, buyouts can actually occur in our model. Fourth, our model allows partners to contractually specify prices ex ante. ${ }^{3}$ Fifth, in our model the optimal type of integration is joint asset ownership, whereas in the GHM model integration always consists of one agent owning both assets. This implies that our concept of integration is subtly different relative to GHM. In our model, decisions under integration require the consent of both partners, whereas in the GHM model, integration gives one agent authority over the other. Moreover, joint asset ownership is never optimal in GHM. Several other models derive conditions for the optimality of joint asset ownership. Cai (2003) examines a model with both specific and general investments, and shows that joint asset ownership becomes optimal when the two types of investments are substitutes. Halonen (2002) provides conditions under which joint asset ownership is optimal in a repeated game framework; see also Blonski and Spagnolo (2003). Our model provides a novel reason for the optimality of joint asset ownership, namely to prevent the dissolution of efficient partnerships.

Our theory provides a fresh perspective on one of the central tenets of transaction cost economics. Williamson $(1975,1985)$ argues that higher asset specificity should lead to integration, providing some verbal reasoning about opportunism and ex post price haggling. More formal theories tend to dismiss these explanations, because rational agents should be able to resolve ex post inefficiencies, and anticipate ex ante any distributional consequences. ${ }^{4}$ Yet, there is strong empirical support that asset specificity is associated with integration. ${ }^{5}$ In our model, binding wealth constraints create ex post inefficiencies that are robust to renegotiation. Asset specificity matters not because of price haggling, but because of partner uncertainty, and its associated displacement and retention externalities. We also augment the standard transaction cost logic by identifying a dynamic trade-off, namely that asset

\footnotetext{
${ }^{1}$ See Grossman and Hart (1986), Hart and Moore (1990), and Hart (1995).

${ }^{2}$ Note, however, that our base model includes private effort. We incorporate a moral-hazard-in-teams problem (Holmström 1982) into our production function. This yields a concave utility frontier as long as the agents' wealth constraints are binding, which generates the ex post inefficiencies.

${ }^{3}$ The non-contractibility of prices is crucial for the property rights theory. We assume that prices are contractible at all times. However, our model does have some contractual incompleteness concerning interim information that allows partners to update their profitability forecasts. If these updates are verifiable, then the optimal allocation of assets becomes state-contingent. Even then the underlying trade-off between displacement and retention externalities remains valid.

${ }^{4}$ Indeed, GHM's property rights theory challenges Williamson's reasoning, arguing that what matters are marginal incentives to increase asset specificity through specific investments (see also Whinston 2003). More recently, several paper develop formal models with costly ex post adjustments, in the spirit of the transaction cost literature. See in particular Bajari and Tadelis (2001), Tadelis (2002), Matouschek (2004), and Casas-Arce and Kittsteiner (2011).

${ }^{5}$ See Lafontaine and Slade (2007) for a comprehensive survey of the empirical literature.
} 
specificity in the current relationship has to be compared against expected asset specificity in a potential future relationship.

A prior literature considers the possibility of ex post inefficiencies. ${ }^{6}$ Of historic interest is that, in addition to their seminal 1986 paper, Grossman and Hart published a less well-known book chapter in 1987 with a model where there are ex post inefficiencies and no specific investments (Grossman and Hart 1987). More recently, Hart (2009) and Hart and Holmström (2010) examine asset ownership in models with "reference points" where in certain states agents can commit to inefficiently withhold cooperation without renegotiation. Aghion et al. (2012) provide a model where renegotiation is hampered by ex post asymmetric information. They show how the ex ante asset allocation plays a role over and above any contractual arrangements.

In our model, ex post inefficiencies derive from a binding wealth constraint. We are not the first to consider wealth constraints. Aghion and Bolton (1992), for example, use them in a financial contracting model. In their model, there are fixed nontransferable private benefits that can lead to ex post inefficient decisions, depending on the allocation of control rights. The main difference to our model is that they focus on financial structures in a single asset model with liquidation, whereas we consider integration decisions in a model with two assets and partner uncertainty.

Joint asset ownership in our model can also be interpreted as a set of mutually exclusive contracts. As such our paper is related to the large literature on exclusive contracting and vertical foreclosure. 7 Aghion and Bolton (1987) examine how a seller can lock buyers into long-term contracts to reduce the threat of entry from a competing seller. Bolton and Whinston (1993) use a property-rights approach to study how concerns about supply assurances can motivate vertical integration. Segal and Whinston (2000) show that exclusive contracts have no effect on specific investments. de Fontenay, Gans, and Groves (2010) further generalize these results. These models typically find that exclusive contracts matter if there is no renegotiation, but that they no longer matter once renegotiation is allowed. In our model there is renegotiation; yet exclusive contracts still matter because renegotiation cannot always achieve the efficient outcome.

Our paper is also related to the emerging literature on the economics of entrepreneurship. One part of this literature examines the formation of partnerships and teams. Prat (2002) considers the benefits of forming heterogeneous teams. Franco Mitchell, Mitchell, and Vereshchagina (2011) identify conditions under which moral hazard leads to assortive matching among team members. Hellmann and Perotti (2011) examine how idea generators are matched with idea developers, both within firms and markets. These theories are mostly concerned with the process by which initial partners form a team. Hellmann and Thiele (2015) further ask at what stage founders actually want to commit to a team. Their theoretical setup is related to the current model, but their focus is on relating the timing of contracting to uncertainty about founder skills.

\footnotetext{
${ }^{6}$ Gibbons (2005) identifies these as adaptation-based theories of the firm. Segal and Whinston (2013) classify them as theories with imperfect bargaining.

${ }^{7}$ See also Jing and Winter (2014) for a broader overview of the literature on exclusionary contracts.
} 
Our model takes some inspiration from the economic literature of marriage and divorce. The work of Brien, Lillard, and Stern (2006) and of Matouschek and Rasul (2008) examine the consequences of changes in the cost of divorce. Peters and Siow (2002), Peters (2007), and Wickelgren (2009) examine the role of wealth and investments in marriage markets. Peters (1986), Friedberg (1998), and Wolfers (2006) look at the effect of unilateral divorce law on the marriage relationship. Our model also involves the matching and rematching of partners, and it also examines the roles of wealth and investments. However, our model is also clearly different from those marriage models. For example, we determine "divorce" costs endogenously, and the role of wealth is entirely different in our model. We develop our model from the ground up, in order to directly address those issues that are relevant in the theory of the firm. 8

The remainder of this paper is structured as follows. The next section introduces our main model. Section III examines how partners make choices about staying versus leaving a relationship, and identifies the optimal asset ownership in the absence of specific investments. In Section IV, we analyze the partners' incentives to make relation-specific investments, and identify the optimal allocation of control rights over critical assets. Since the optimal ownership arrangement depends on the wealth of the partners used for transfer payments, we also address the difficulties of changing the amount available for such transfers. In Section V, we discuss how allowing for asymmetric partners would affect our main insights. Section VI discusses testable empirical predictions of the model. It is followed by a brief conclusion that summarizes the main results and explores avenues for future theory work. All proofs are in the online Appendix.

\section{The Base Model}

Consider an initial match of two risk-neutral partners, for ease of exposition called Alice $(A)$ and Bob $(B)$. For example, Bob can be the owner of an upstream firm selling an input to Alice as the owner of a downstream firm, which Alice needs to manufacture an end product. The value of their initial outside options is normalized to zero. Each partner initially owns a co-specialized asset, and has wealth $w \equiv w_{A}=w_{B} \geq 0$.

There are five dates. See Figure 1 for a graphical overview. At date 0, both partners decide on an ownership structure for both assets. While we consider all ownership structures, the key decision will be whether partners keep individual asset ownership, or they agree on joint asset ownership. 9 At date 1, both partners can

\footnotetext{
${ }^{8}$ In this context it is also worth mentioning the small literature on dissolutions of partnerships, which presumes that there is prior joint ownership, but that the partners now want to dissolve their partnership. This literature focuses on information asymmetries across partners, and examines alternative auction mechanisms for how to dissolve the partnership. See in particular the work Cramton, Gibbons, and Klemperer (1987); McAfee (1992); and de Frutos and Kittsteiner (2008).

${ }^{9}$ Joint asset ownership in our setting gives both partners mutual control rights over their assets, which is fundamentally different from integration in the GHM models, where one partner owns both assets. In the Appendix we also discuss the role of long-term contracts where asset owners can commit to future transaction prices. We ask whether such contracts can be used to structure more efficient ex ante arrangements. However, we find that compared to joint asset ownership, a long-term contract cannot improve ex ante efficiency. Hence our focus on individual versus joint ownership.
} 


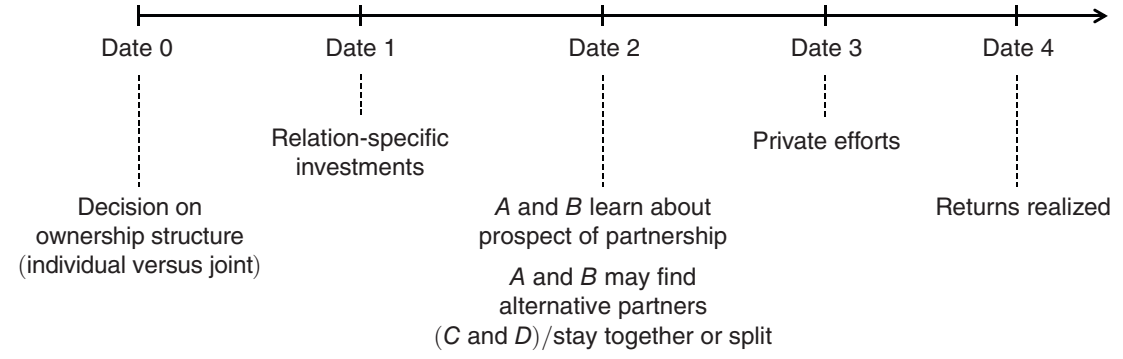

Figure 1. Timeline

make relation-specific investments to improve the value of joint production. At date 2, Alice and Bob learn about the prospect of their partnership, and may find alternative partners. They then decide whether to stay together, or to leave and form a new partnership. Alice and Bob may also renegotiate any division of surplus. At date 3, partners exert private effort to produce output. Finally, at date 4, all returns are realized.

In case of a successful joint production, Alice and Bob generate the profit $y$ at date 4 . We assume that $y$ is verifiable, and that it has a distribution $\Omega_{\text {in }}(y)$ over some interval $y \in[\underline{y}, \bar{y}]$ with $0 \leq \underline{y}<\bar{y} \leq \infty$. We denote the expected value by $\pi=\int_{y}^{\bar{y}} y d \Omega_{\text {in }}(y)$, and refer to it as the inside prospect of the match between Alice and Bob. We assume that the inside prospect $\pi$ is observable by both partners, but non-verifiable by outside parties.

At date 1 Alice and Bob can invest in their relationship to improve the distribution of potential profits $y$. Specifically we assume that the expected profit $\pi$ can take on two values: $\pi \in\left\{\pi_{L}, \pi_{H}\right\}$, with $\pi_{H}>\pi_{L}>0$. The inside prospect $\pi$ will be high $\left(\pi=\pi_{H}\right)$ with probability $p=p\left(r_{A}, r_{B}\right)$, and low $\left(\pi=\pi_{L}\right)$ with probability $1-p$, where $p$ is concave increasing in the partners' relation-specific investments $r_{A}$ and $r_{B}$. Specific investments are non-contractible, and impose convex private costs $\psi\left(r_{i}\right), i=A, B$, with $\psi(0)=\psi^{\prime}(0)=0$. To ensure interior solutions we assume that $p(0,0)=0$ and $\partial p(\cdot) /\left.\partial r_{i}\right|_{r_{i}=0}=\infty, i=A, B$. We also assume that the cross-partial is not too negative: $\partial^{2} p(\cdot) /\left(\partial r_{A} \partial r_{B}\right)>-\kappa$, where $\kappa>0$. This ensures that the reaction functions of both partners are well-behaved. ${ }^{10}$ Alice and Bob learn the actual inside prospect $\pi \in\left\{\pi_{L}, \pi_{H}\right\}$ at date 2 .

Depending on the observed inside prospect $\pi \in\left\{\pi_{L}, \pi_{H}\right\}$ at date 2, Alice and Bob can decide to break their original partnership and match with alternative partners. Specifically, we assume that Alice finds an alternative partner, called Charles $(C)$, with probability $q>0$. We assume symmetry so that Bob discovers an alternative partner, called Dora $(D)$, with the same (but independent) probability $q .11$

\footnotetext{
${ }^{10} \mathrm{~A}$ sufficient and intuitive assumption is that the specific investments $r_{A}$ and $r_{B}$ are (weak) strategic complements, so that $\partial^{2} p(\cdot) /\left(\partial r_{A} \partial r_{B}\right) \geq 0$.

${ }^{11}$ Recall that Alice and Bob have complementary assets which both are needed for production. This excludes the possibility of Alice partnering with Dora, or Bob partnering with Charles.
} 
For simplicity, we assume that both alternative partners, Charles and Dora, have zero wealth, and normalize their outside options to zero. The profit $y$ of a successful alternative partnership has the distribution $\Omega_{\text {out }}(y)$. We denote the expected value by $\sigma=\int y d \Omega_{\text {out }}(y)$, which we refer to as the outside prospect.

At date 3 the partners engage in joint production. This can be either Alice and Bob $(A, B)$, or Alice and Charles $(A, C)$ and/or Bob and Dora $(B, D)$. Joint production requires (i) the use of both of the partners' complementary assets, and (ii) their private efforts, which we denote $e_{i}, i=A, B, C, D$. A partner's disutility of effort is $c\left(e_{i}\right)$, with $c^{\prime}\left(e_{i}\right)>0, c^{\prime \prime}\left(e_{i}\right)>0$, and $c(0)=c^{\prime}(0)=0$. Production either generates a joint profit at date 4 (success), or no profit at all (failure). The success probability is given by $\mu\left(e_{i} e_{j}\right), i, j \in\{\{A, B\},\{A, C\},\{B, D\}\}$, which is increasing and concave in its argument $e_{i} e_{j}$, with $\mu(0)=0$. Thus, the partners' efforts are complementary, and success requires that both partners apply strictly positive efforts (i.e., $e_{i}, e_{j}>0$ ).

The realized profit $y$ at date 4 can be divided between the two partners according to any sharing rule, where Alice obtains $\alpha y$ and Bob receives $\beta y$, with $\alpha+\beta=1$. Depending on the ownership structure this sharing rule can be implemented in different ways. Under joint asset ownership, we think of $\alpha$ and $\beta$ as a division of ownership shares from the jointly owned venture. Under individual asset ownership there are no ownership shares, so the division of surplus comes from some transfer price. ${ }^{12}$

Ownership defines control rights over the productive assets. We assume that Alice and Bob initially have full rights of control over their respective assets. Alice and Bob can then choose to retain their control rights at date 0 (individual asset ownership); they can then simply wait until date 2 to see whether in fact they want to partner up. If they do, they negotiate a transfer price that determines their profit shares $(\alpha, \beta)$ at that time. Alternatively, the partners can agree at date 0 to share control rights over both assets (joint asset ownership). This requires that Alice and Bob negotiate the ownership shares $\alpha$ and $\beta$ at date 0 (we discuss in the online Appendix why we can limit ourselves to individual and joint asset ownership). Ownership matters because it affects the ability of a partner to leave. Under individual asset ownership, a partner with a superior outside option can always leave without the consent of the other. Under joint asset ownership, the two partners share control rights over both assets, so that leaving requires consent of the other partner.

The two initial partners, Alice and Bob, determine asset ownership at date 0 . Bargaining can also occur at date 2, where it may involve two or more parties. Because of a potentially binding wealth constraint (in case each partner's initial wealth $w$ is sufficiently low), we need a bargaining solution for games with nontransferable utilities. We adopt the bargaining protocol of Hart and Mas-Colell (1996), where in each round one member at the bargaining table is selected at random to

\footnotetext{
${ }^{12}$ In principle it is possible to make $\alpha$ and $\beta$ contingent on $y$. In the case of joint asset ownership, it is easy to verify that for any division of surplus with variable $\alpha$ and $\beta$, there exists an equivalent division of surplus with a constant $\alpha$ and $\beta$. Without loss of generality we can therefore focus on constant $\alpha \mathrm{s}$ and $\beta \mathrm{s}$. In the case of individual asset ownership, $\alpha$ and $\beta$ depend on how transfer prices are specified, i.e., how they depend on the realization of $y$. To keep our notation as simple as possible we focus on the case of constant $\alpha$ s and $\beta$ s. This is without loss of generality since all that matters is the expected profit share at date 2 .
} 
make a proposal, and where there is a small probability that a partner whose proposal was rejected is permanently eliminated from the bargaining. ${ }^{13}$ This bargaining protocol generates the Maschler-Owen consistent NTU value, which is a generalization of the Shapley value for games with non-transferable utility (Maschler and Owen 1992). For bilateral bargaining games, the Maschler-Owen consistent NTU value reduces to the Nash bargaining solution. ${ }^{14}$

We assume that the only members at the bargaining table are those who have the control rights to affect the decision. This means that under individual asset ownership, bargaining takes place between the two partners who want to engage in joint production. Under joint asset ownership, however, leaving requires the consent of the other partner. A new partner (Charles or Dora) therefore has to engage in trilateral bargaining with both of the original partners (Alice and Bob). In the online Appendix, we show that alternative bargaining protocols may generate different levels of utility, but they do not affect the basic logic of how partners make optimal asset ownership decisions.

\section{The Role of Asset Ownership}

We first analyze how asset ownership affects the renegotiation outcome between Alice and Bob at date 2, and therefore their decision to stay together or to match with alternative partners. We then identify the optimal asset ownership that Alice and Bob agree on at date 0 . To show that our key insights do not rely on specific investments, we deliberately shut down this part of the model until Section IV, and assume for now that the probability of a high inside prospect, $p$, is fixed.

\section{A. Joint Production}

In our model, there is team production. ${ }^{15}$ Alice and Bob choose their respective efforts $e_{A}$ and $e_{B}$ to maximize their expected utilities: 16

$$
\begin{aligned}
& \max _{e_{A}} U_{A}(\alpha ; \pi)=\alpha \mu\left(e_{A} e_{B}\right) \pi-c\left(e_{A}\right) ; \\
& \max _{e_{B}} U_{B}(\beta ; \pi)=\beta \mu\left(e_{A} e_{B}\right) \pi-c\left(e_{B}\right) .
\end{aligned}
$$

The analysis is analogous for joint production with a new partner (Charles or Dora) except that the inside prospect $\pi \in\left\{\pi_{L}, \pi_{H}\right\}$ is to be replaced by the outside prospect $\sigma$.

Figure 2 illustrates the utility-possibility frontier for different profit shares $\alpha$ and $\beta=1-\alpha$. The frontier is backward bending because every partner relies on the productive effort of his co-partner. If one partner exerts no effort (which occurs

\footnotetext{
${ }^{13}$ This is a multiplayer generalization of the breakdown game by Binmore, Rubinstein, and Wolinsky (1986).

${ }^{14}$ For a more extensive discussion of this, see Hart (2004).

${ }^{15}$ Because of the binary nature of outcomes (success or failure), there is no possibility for budget breaking as in Holmström (1982).

${ }^{16}$ Note that wealth $w$ will only indirectly affect the partners' effort incentives when it is used for transfer payments to change the profit shares $\alpha$ and $\beta$; we discuss this in more detail in Section IIIC.
} 


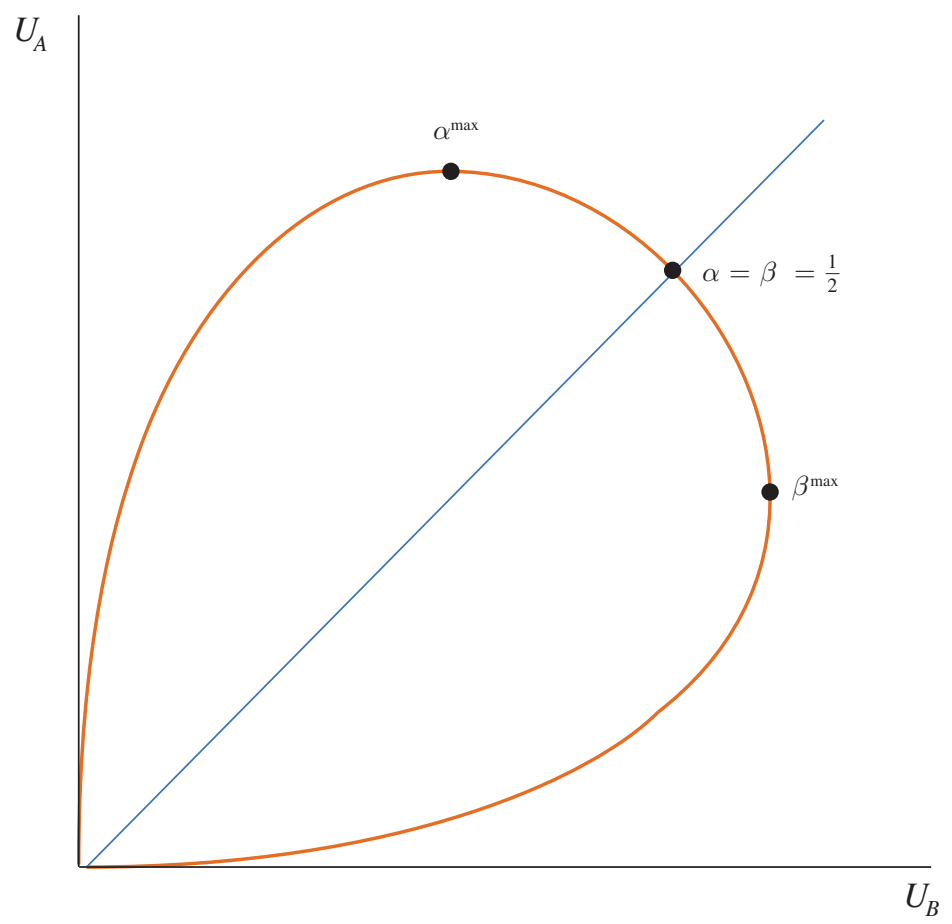

Figure 2. Utility-Possibility Frontier for JoInt Production

when $\alpha \in\{0,1\})$, joint production never succeeds $(\mu(0)=0)$, and Alice and Bob both get a zero utility. We can also see from Figure 2 that the total surplus is maximized when each (symmetric) partner gets exactly half of the expected profit $\pi(\alpha=\beta=1 / 2)$. We formally prove this in the online Appendix. However, each partner prefers to get more than half of the expected profit, i.e., the individually optimal profit shares for Alice and Bob satisfy $\alpha^{\max }=\beta^{\max }>1 / 2$.

\section{B. Symmetric Outside Options}

We can now analyze how the allocation of control rights over the two assets affects Alice's and Bob's decision at date 2 to stay together or to dissolve their partnership. For this we first consider the outcome in case they have identical outside options.

If neither Alice nor Bob found an alternative partner, which occurs with probability $(1-q)^{2}$, joint production is the only option. Because of symmetry, both partners share the profits equally, so that $\alpha^{*}=\beta^{*}=1 / 2$. For this case, we denote the expected utility of each partner by $U(\pi) \equiv U_{A}(\pi)=U_{B}(\pi)$.

Now suppose that Alice and Bob each found an alternative partner, which occurs with probability $q^{2}$. If Alice and Bob decide to stay together, they agree on $\alpha^{*}=\beta^{*}=1 / 2$. The expected utility for each partners is then $U(\pi)$. Alternatively, Alice and Bob can decide to match with Charles and Dora, respectively. They then bargain over the division of the expected profit $\sigma$ from their new partnerships. Recall 
that the alternative partners, Charles and Dora, both have zero outside options. The same applies to Alice and Bob during the bargaining. ${ }^{17}$ The Nash bargaining solution then implies that the profit shares for Alice and Bob in their new partnerships are given by $\hat{\alpha}=\hat{\beta}=1 / 2$. $^{18}$ For this case we denote expected utility of each partner by $U(\sigma)$.

It is straightforward to show that $U(\sigma)=U(\pi)$ when $\sigma=\pi \in\left\{\pi_{L}, \pi_{H}\right\}$. Thus, Alice and Bob stay together (joint production) with $\alpha^{*}=\beta^{*}=1 / 2$ as long as $\pi \geq \sigma$. Otherwise they dissolve their partnership, and match with their alternative partners Charles and Dora. And because leaving is mutually beneficial for $\sigma>\pi$, it is irrelevant whether they agreed on individual or joint asset ownership at date 0 .

\section{Asymmetric Outside Options}

The most interesting scenario arises when only one partner found an alternative partner at date 2. We discuss the implications of individual and joint asset ownership separately.

Individual Asset Ownership.- - Suppose Alice and Bob agreed on individual asset ownership at date 0 , and without loss of generality assume that only Alice found an alternative partner at date 2, Charles. To identify potential inefficiencies that may then arise, we first consider the case where Alice and Bob have no initial wealth $(w=0)$. We then relax this assumption and show how Alice and Bob can use their wealth to (partially) offset these inefficiencies.

Individual asset ownership allows Alice to unilaterally take her asset and form a new partnership with Charles without Bob's consent. Alice's outside option when bargaining with her alternative partner Charles is to go back to Bob, and gives a utility of $U(\pi) .{ }^{19}$ Let $\hat{\alpha}_{I}$ denote the equilibrium profit share for Alice when partnering with Charles, where the subscript " $I$ " indicates individual asset ownership. 20 Alice's expected utility is then $U_{A}\left(\hat{\alpha}_{I} ; \sigma\right)$.

When Alice leaves Bob and matches with Charles, Bob's expected utility becomes $U_{B}=0$. This is clearly smaller than his expected utility $U_{B}(\pi)$ under joint production with Alice. Thus, Alice imposes a displacement externality on Bob when displacing him with the alternative partner Charles. Leaving Bob is jointly inefficient when $U_{A}\left(\hat{\alpha}_{I} ; \sigma\right)<2 U(\pi)$.

\footnotetext{
${ }^{17}$ Intuitively, when negotiating a deal with Charles, Alice expects to close a deal, so she would not consider going back to Bob. Thus, Bob's outside option is zero when negotiating a deal with Dora at the same time, and vice versa. Technically, under the Hart and Mas-Colell bargaining protocol, there is an $\varepsilon$ probability that the bargaining fails. Thus, with probability $\varepsilon$, Alice has the fall-back option of going back to Bob, and vice versa. The Hart and Mas-Colell bargaining protocol then assumes that $\varepsilon \rightarrow 0$, implying that Alice's and Bob's outside options converge to zero.

${ }^{18}$ Throughout the paper we use an asterisk $(*)$ to indicate equilibrium profit shares under joint production (Alice-Bob match); a hat $(\wedge)$ indicates the equilibrium profit shares in alternative matches (either Alice-Charles match, or Bob-Dora match).

${ }^{19}$ According to the Hart and Mas-Colell bargaining protocol, this outside option would only be realized if the bargaining between Alice and Charles breaks down, so that Alice loses Charles as a potential trading partner. In this case, both Alice and Bob would have zero outside options, so that they split the equity in half.

${ }^{20}$ More formally, $\hat{\alpha}_{I}$ maximizes the Nash product $\left[U_{A}\left(\hat{\alpha}_{I} ; \sigma\right)-U(\pi)\right]^{1 / 2}\left[U_{C}\left(1-\hat{\alpha}_{I} ; \sigma\right)\right]^{1 / 2}$. It is easy to see that for any $U(\pi)>0$ we have $\hat{\alpha}_{I} \in(1 / 2,1)$.
} 
Alice could also stay with Bob but use her better outside option (switching to Charles) to renegotiate a higher profit share. The outside option of Alice when renegotiating with Bob is given by $U(\sigma)$. Let $\alpha_{I}^{*}$ denote the equilibrium profit share for Alice when staying with Bob. ${ }^{21}$ The renegotiation then leads to the expected utility $U_{A}\left(\alpha_{I}^{*} ; \pi\right)$ for Alice and $U_{B}\left(\beta_{I}^{*} ; \pi\right)$ for Bob, with $\beta_{I}^{*}=1-\alpha_{I}^{*}$. Relative to the equal division of profits with $\alpha=\beta=1 / 2$, this outcome is more favorable to Alice, and less favorable to Bob. Most importantly, it is jointly inefficient since joint surplus is maximized at $\alpha=\beta=1 / 2$.

Whether the partner with the outside option stays or leaves the initial partnership depends on the inside project $\pi \in\left\{\pi_{L}, \pi_{H}\right\}$ that the two partners observe at date 2 . In the online Appendix, we derive a threshold of the inside prospect, $\hat{\pi}_{I}(\sigma)=\sigma$, so that asymmetric outside options under individual asset ownership with zero wealth lead to displacement when $\pi<\hat{\pi}_{I}(\sigma)$, and unequal profit shares when $\pi \geq \hat{\pi}_{I}(\sigma)$.

If Alice and Bob have some wealth $w>0$, they could make transfer payments to (partially) offset these inefficiencies. With unlimited wealth the ex post inefficiencies can be completely eliminated (Alice then stays with $\alpha=\beta=1 / 2$ ). In the online Appendix, we characterize the minimum amount of wealth, denoted $\bar{w}_{I}$, that is required to fully eliminate the inefficiencies. We also characterize $\underline{w}_{I} \geq 0$ as the lower bound, below which wealth cannot change the renegotiation outcome at all (Alice still prefers to partner with Charles).

LEMMA 1: Consider individual asset ownership and suppose that the two original partners have asymmetric outside options. Then, there exists a threshold $\hat{\pi}_{I}(\sigma, w)$, such that the partner with the better outside option leaves if $\pi<\hat{\pi}_{I}(\sigma, w)$. Otherwise, if $\pi \geq \hat{\pi}_{I}(\sigma, w)$, he stays, but renegotiates his share on the expected joint profit $\pi$. The threshold $\hat{\pi}_{I}(\sigma, w)$ is decreasing in wealth $w$ for $\underline{w}_{I} \leq w<\bar{w}_{I}$.

Joint production between Alice and Bob is the outcome under individual asset ownership with asymmetric outside options whenever the inside prospect $\pi$ is sufficiently high $\left(\pi \geq \hat{\pi}_{I}(\sigma, w)\right)$. The partner with the better outside option then renegotiates the division of surplus, which is optimal from a selfish perspective but compromises the efficiency of joint production (as long as the partners do not have sufficient wealth for transfers to settle on an equal split of profits). Displacement, on the other hand, occurs whenever the prospect of the original partnership is sufficiently low $\left(\pi<\hat{\pi}_{I}(\sigma, w)\right)$. This imposes a displacement externality on the partner without outside option.

The effect of more initial wealth $w$ is to allow the partner without outside option to offer a larger transfer payment. This makes staying (with renegotiation) more attractive for the partner with the outside option. As a consequence the region where the original partners stay together is larger, i.e., the critical value $\hat{\pi}_{I}$ becomes smaller.

Joint Asset Ownership.-Next we consider joint asset ownership. In the seminal work of Grossman, Hart, and Moore, joint asset ownership is never optimal, and

\footnotetext{
${ }^{21}$ Using Nash bargaining, $\alpha_{I}^{*}$ maximizes $\left[U_{A}\left(\alpha_{I}^{*} ; \pi\right)-U(\sigma)\right]^{1 / 2}\left[U_{B}\left(1-\alpha_{I}^{*} ; \pi\right)\right]^{1 / 2}$. Moreover, note that $U(\sigma)>0$ implies $\alpha_{I}^{*} \in(1 / 2,1)$.
} 
integration involves one agent controlling both assets. In our model, however, integration is best achieved with joint asset ownership, where the two partners need each other's consent to deploy their assets elsewhere.

We focus again on the asymmetric constellation at date 2, and without loss of generality assume that only Alice found an alternative partner, namely Charles. Therefore Alice wants to leave Bob. Without wealth, Alice can only buy out her asset by offering Bob a share on the future return $\sigma$ from her new partnership with Charles. Productive effort is then only applied by Alice and Charles, so that Bob is a shareholder who does not add any value. We define $\hat{\alpha}_{J}$ and $\hat{\beta}_{J}$ as the equilibrium shares on the return $\sigma$ for Alice and Bob, respectively. The equilibrium share for Charles is denoted by $\hat{\gamma}_{J} \cdot{ }^{22}$ For this scenario we denote the expected utility for Alice as $U_{A}\left(\hat{\alpha}_{J} ; \sigma\right)$ and for Bob as $U_{B}\left(\hat{\beta}_{J} ; \sigma\right)$. This buyout arrangement impairs effort incentives, and thus lowers the expected payoff from Alice's partnership with Charles.

However, the profit share $\hat{\beta}_{J}$ offered to Bob may not suffice to buy his consent, so that Alice is forced to stay despite leaving being jointly efficient, which is the case when $U(\sigma)>2 U(\pi)$. Bob then imposes a retention externality on Alice.

Which of the two inefficiencies-inefficient buyout or retention-arises in equilibrium, depends again on the inside project $\pi \in\left\{\pi_{L}, \pi_{H}\right\}$ that Alice and Bob observe at date 2. In the online Appendix, we characterize the threshold $\hat{\pi}_{J}(\sigma)$, so that asymmetric outside options under joint asset ownership with zero wealth lead to retention when $\pi \geq \hat{\pi}_{J}(\sigma)$, and inefficient buyout when $\pi<\hat{\pi}_{J}(\sigma)$.

When Alice and Bob have some wealth $w>0$, they can make side payments to mitigate these inefficiencies. In the online Appendix, we characterize the minimum amount of wealth, denoted $\bar{w}_{J}$, that is necessary to eliminate all ex post inefficiencies under joint asset ownership (Alice can buy out her asset without offering Bob a profit share). Likewise we characterize the lower bound of wealth, $\underline{w}_{J} \geq 0$, below which wealth cannot affect the renegotiation outcome at all (the transfer is not enough for Bob to let Alice go).

LEMMA 2: Consider joint asset ownership and suppose that the two original partners have asymmetric outside options. Then, there exists a threshold $\hat{\pi}_{J}(\sigma, w)$, such that the partner with the better outside option leaves with consent if $\pi<\hat{\pi}_{J}(\sigma, w)$. Otherwise, if $\pi \geq \hat{\pi}_{J}(\sigma, w)$, he stays with $\alpha^{*}=\beta^{*}=1 / 2$. The threshold $\hat{\pi}_{J}(\sigma, w)$ is increasing in wealth $w$ for $\underline{w}_{J} \leq w<\bar{w}_{J}$.

Joint production between Alice and Bob is the equilibrium outcome as long as the inside prospect $\pi$ is sufficiently high $\left(\pi \geq \hat{\pi}_{J}(\sigma, w)\right)$. They then split everything in half $\left(\alpha^{*}=\beta^{*}=1 / 2\right)$, so that total surplus is maximized. In contrast, Alice and Bob agree to break up whenever the alternative partnership is attractive enough $\left(\pi<\hat{\pi}_{J}(\sigma, w)\right)$. Unless the partner with the better outside option, say Alice, has sufficient wealth $\left(w \geq \bar{w}_{J}\right)$, she needs to offer Bob a stake in the new partnership with Charles in exchange for regaining control rights over her asset. The effect of

\footnotetext{
${ }^{22}$ We provide a complete characterization of $\hat{\alpha}_{J}, \hat{\beta}_{J}$, and $\hat{\gamma}_{J}$ in the online Appendix, using the Maschler-Owen consistent NTU value.
} 
more wealth $w$ is to enable Alice to make larger payments to Bob, thereby allowing her to retain more of the equity of the new partnership with Charles. This makes the buyout option more attractive, and leaving occurs for a larger range of parameters, i.e., the critical value $\hat{\pi}_{J}$ is increasing in $w$.

\section{Optimal Asset Ownership}

With symmetric outside options, it is irrelevant whether Alice and Bob agreed on individual or joint asset ownership; the outcome is always jointly efficient. Only for asymmetric outside options and binding wealth constraints the allocation of control rights matters.

PROPOSITION 1: Suppose $w<\min \left\{\bar{w}_{I}, \bar{w}_{J}\right\}$. Then, there exists a threshold $\hat{\pi}_{V}(\sigma)$, such that the contract choice for the two partners at date 0 is as follows:

(i) For $\pi_{L}, \pi_{H}<\hat{\pi}_{V}(\sigma)$, they choose individual asset ownership.

(ii) For $\pi_{L}, \pi_{H} \geq \hat{\pi}_{V}(\sigma)$, they choose joint asset ownership.

(iii) For $\pi_{L}<\hat{\pi}_{V}(\sigma)<\pi_{H}$, there exists a threshold $\hat{p} \in(0,1)$, such that both partners choose joint asset ownership at date 0 whenever $p \geq \hat{p}$; otherwise they choose individual asset ownership.

The threshold $\hat{\pi}_{V}(\sigma)$ satisfies $\hat{\pi}_{J}(\sigma, w)<\hat{\pi}_{V}(\sigma)<\hat{\pi}_{I}(\sigma, w)$, and is increasing in $\sigma$.

For now let us focus on the scenarios (i) and (ii) to explain the rationale behind Proposition 1. For this we refer to Figure 3, which presumes that Alice and Bob have asymmetric outside options at date 2. Dissolving their partnership is then jointly efficient if the inside prospect is sufficiently low $\left(\pi<\hat{\pi}_{V}(\sigma)\right)$; otherwise joint production with an equal split of profits maximizes joint surplus.

Consider regions $(I)$ and $(I I)$. In these two regions the inside prospect $\pi$ is sufficiently high, so that Alice's and Bob's joint utility is maximized when they remain together. Under individual asset ownership there is a displacement externality. In region $(I I)$, the outside prospect $\sigma$ is sufficiently attractive, so that the partner with outside option simply leaves without renegotiation. In region $(I)$, the partner with outside option merely uses his opportunity to switch as a bargaining chip. Both of these outcomes are ex post inefficient from a joint perspective. These inefficiencies can be avoided with joint asset ownership, where Alice and Bob always remain together without renegotiation.

In regions $(I I I)$ and $(I V)$, the inside prospect is weak relative to the outside prospect, so that dissolving the partnership in case of asymmetric outside options would maximize Alice's and Bob's joint surplus. In region $(I V)$, the partner with outside option has to buy himself free under joint asset ownership, which compromises effort incentives in his new partnership. However, in region $(I I I)$, the outside prospect is not high enough to warrant a buyout. As a consequence, the partner without 


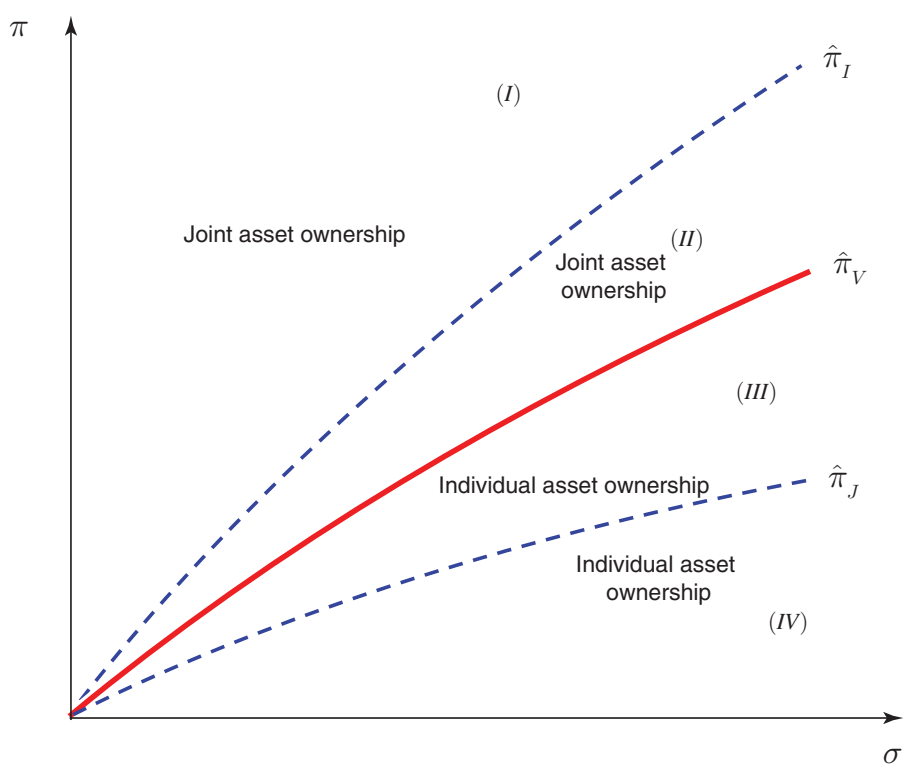

Figure 3. AsSET OwnERShIP AND JoInt EFFICIENCY

outside option inefficiently retains the other. Obviously, these retention inefficiencies can be avoided with individual asset ownership.

Now consider the most interesting scenario (iii) from Proposition 1. Alice and Bob then choose joint asset ownership if the inside prospect $\pi$ is likely to be high $(p \geq \hat{p}$ ), because preserving the partnership is likely to be valuable. Otherwise they choose individual asset ownership in order to retain the flexibility to dissolve a likely inefficient partnership $(p<\hat{p})$. Thus, the threshold $\hat{p}$ balances (i) the risk of preserving inefficient partnerships (joint ownership with $\pi=\pi_{L}$ ), and (ii) the risk of compromising otherwise efficient partnerships (individual ownership with $\pi=\pi_{H}$ ). Overall we note that for this scenario the ex ante optimal allocation of control rights can lead to ex post inefficiencies, namely a displacement inefficiency (individual ownership), associated with regions $(I)$ and $(I I)$ in Figure 3, and a retention externality (joint ownership), associated with regions (III) and $(I V)$.

If the internal learning process was based on verifiable signals so that an ex ante contract can distinguish between $\pi=\pi_{L}$ and $\pi=\pi_{H}$, then Alice and Bob could write a contingent contract that stipulates individual asset ownership at date 2 whenever $\pi=\pi_{L}<\hat{\pi}_{V}(\sigma)$, and joint asset ownership whenever $\pi=\pi_{H} \geq \hat{\pi}_{V}(\sigma)$. For the remainder of this paper we assume that $\pi$ is non-verifiable, which seems very plausible within the present context, given that learning about the inside prospect is specific to the collaboration of the two partners. Moreover, we focus on the most interesting scenario, where $\pi_{L}<\hat{\pi}_{V}(\sigma)<$ $\pi_{H}$. This implies that the ex ante decision over asset ownership involves a trade-off between the flexibility of individual asset ownership versus the commitment value of joint asset ownership. 


\section{Model with Relation-Specific Investments}

\section{A. Optimal Investments}

We now augment our model and allow Alice and Bob to make relation-specific investments at date 1. We first examine the optimal choice of investments. Both partners are symmetric at date 1, so that in equilibrium they choose the same level of specific investment. We define $r_{I}^{*}(w)$ as the equilibrium relation-specific investment of a partner under individual asset ownership, and $r_{J}^{*}(w)$ as the equilibrium investment under joint asset ownership. We provide a complete characterization of the partners' expected utilities and the equilibrium investment levels, $r_{I}^{*}(w)$ and $r_{J}^{*}(w)$, in the online Appendix (see Proof of Proposition 2).

The next proposition compares the specific investments under individual asset ownership $\left(r_{I}^{*}(w)\right)$ and joint asset ownership $\left(r_{J}^{*}(w)\right)$ for different wealth levels. We assume that Alice and Bob are always willing to use their entire wealth to mitigate ex post inefficiencies. 23

PROPOSITION 2: For $w<\max \left\{\bar{w}_{I}, \bar{w}_{J}\right\}$, joint asset ownership provides greater incentives for relation-specific investments, i.e., $r_{J}^{*}(w)>r_{I}^{*}(w)$. Moreover:

(i) $r_{J}^{*}(w)$ is decreasing in the partners'wealth $w$ for $\underline{w}_{J} \leq w<\bar{w}_{J}$, and

(ii) $r_{I}^{*}(w)$ is increasing in the partners' wealth $w$ for $\underline{w}_{I} \leq w<\bar{w}_{I}$.

For $w \geq \max \left\{\bar{w}_{I}, \bar{w}_{J}\right\}$, relation-specific investments are identical and constant under individual and joint asset ownership, i.e., $r_{I}^{*}(w)=r_{J}^{*}(w)$.

Figure 4 illustrates the insights from Proposition 2 (allowing for all renegotiation scenarios: $\underline{w}_{i}=0$ and $\left.\underline{w}_{i}>0, i=I, J\right)$. To explain the key intuition, let us first focus on the case with zero wealth $(w=0)$, so that Alice and Bob cannot make any ex post transfers. With joint asset ownership, the partner combination is always efficient when the inside prospect is high, but leads to inefficient retention when the inside prospect is low. The latter inefficiency of joint asset ownership widens the difference in utilities between a low and a high inside prospect. With individual asset ownership, the partner combination is always efficient when the inside prospect is low, but causes displacement problems when the inside prospect is high. The latter inefficiency of individual asset ownership narrows the difference in utilities between a low and a high inside prospect. We therefore find that joint asset ownership provides stronger incentives for specific investments $\left(r_{J}^{*}(0)>r_{I}^{*}(0)\right)$, precisely because the inefficiency then arises when the partners have failed to develop a strong internal relationship.

The next question is what happens to specific investments when Alice and Bob have some initial wealth $w>0$ ? Under individual asset ownership, wealth allows

\footnotetext{
${ }^{23}$ From an ex post perspective, it is always optimal for the two partners to use their entire wealth (up to $\bar{w}_{I}$ or $\bar{w}_{J}$ ) to reduce ex post inefficiencies. In Section IVC we discuss how the partners can either limit the use of their wealth for ex post transfer payments, or raise additional money from outside investors to make such transfers.
} 

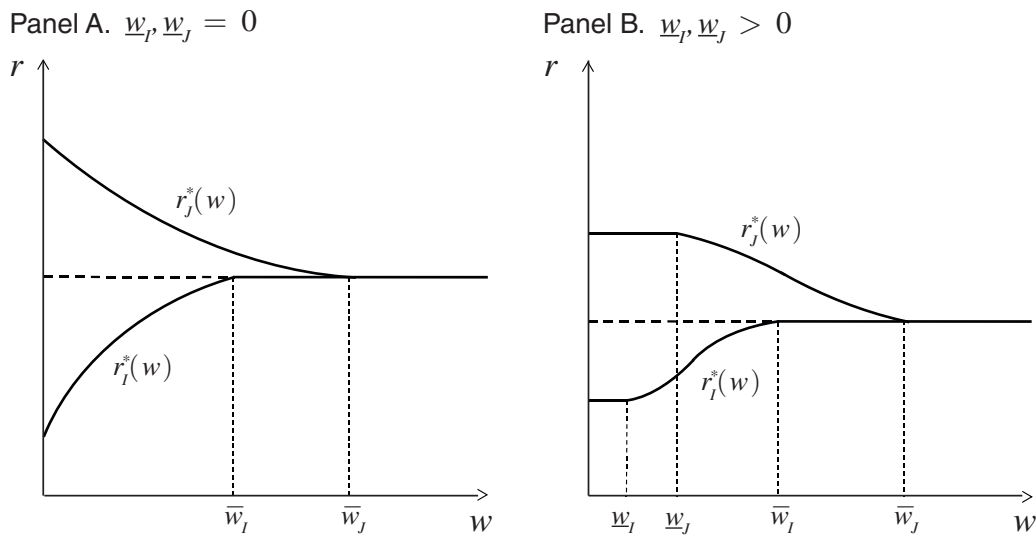

Figure 4. Wealth and Relation-Specific Investments

them to smooth out ex post inefficiencies in the good state $\pi=\pi_{H}$. This improves the marginal benefit of specific investments, so that $r_{I}^{*}(w)$ is increasing in $w$. Under joint asset ownership, wealth helps Alice and Bob to correct ex post inefficiencies in the bad state $\pi=\pi_{L}$. This makes the difference between the bad and the good state relatively smaller, and therefore compromises Alice's and Bob's incentives to make relation-specific investments. Thus, $r_{J}^{*}(w)$ decreases in $w$, while $r_{I}^{*}(w)$ increases.

Alice and Bob can eliminate all ex post inefficiencies in case of asymmetric outside options when they have sufficient $\left(w \geq \max \left\{\bar{w}_{I}, \bar{w}_{J}\right\}\right)$. That is, with enough wealth they can always dissolve their partnership in the bad state $\left(\pi_{L}\right)$, so that $V\left(\pi_{L}\right)=U(\sigma)$; and they can always agree on staying together with an equal split of profits in the good state $\left(\pi_{H}\right)$, so that $V\left(\pi_{H}\right)=2 U(\pi)$. The allocation of control rights is then irrelevant, and the marginal incentives for specific investments are the same $\left(r_{I}^{*}(w)=r_{J}^{*}(w)\right)$.

\section{B. Optimal Asset Ownership}

We now turn to the analysis of the optimal ownership structure for Alice and Bob, accounting for specific investments and potential ex post transfers. For this we characterize Alice's and Bob's expected utilities as a function of their wealth $w$, assuming again that they use their entire wealth (up to $\bar{w}_{I}$ or $\bar{w}_{J}$ ) at date 2 to mitigate any ex post inefficiencies. ${ }^{24}$

LEMMA 3: Under individual asset ownership, the expected utility of a partner at date 0 , denoted by $E U_{I}(w)$, has three distinct segments:

(i) For $w<\underline{w}_{I}, E U_{I}(w)$ is constant in $w$.

\footnotetext{
${ }^{24}$ The expected utility is obviously increasing in wealth itself, so we focus on the expected utility from the productive activities, net of initial wealth. This expected utility still depends on wealth, since wealth affects both incentives and ex post payoffs.
} 
(ii) For $\underline{w}_{I} \leq w<\underline{w}_{I}, E U_{I}(w)$ is strictly increasing in $w$.

(iii) For $w \geq \bar{w}_{I}, E U_{I}(w)$ is constant in $w$.

The previous sections identified two distinct facets of wealth. On the one hand, having wealth allows Alice and Bob to mitigate potential inefficiencies arising from asymmetric outside options; and doing so is always optimal ex post. On the other hand, having wealth affects their incentives for relation-specific investments. Under individual asset ownership, the ex post efficiency effect of wealth and the incentive effect of wealth both go in the same direction. More wealth improves the ex post renegotiation outcome (at date 2). It also improves ex ante incentives for specific investments (at date 1) because the inefficiencies are associated with a high inside prospect. The expected utility $E U_{I}(w)$ is therefore increasing in wealth $w$ in the range $w \in\left[\underline{w}_{I}, \bar{w}_{I}\right)$, and constant everywhere else.

We now turn to joint asset ownership. For the next lemma we define $w_{J}^{*}$ as the wealth level that maximizes the expected utility of a partner under joint ownership at date 0 .

LEMMA 4: Under joint asset ownership, the expected utility of a partner at date 0, denoted by $E U_{J}(w)$, has the following properties:

(i) For $w<\underline{w}_{J}, E U_{J}(w)$ is constant in $w$.

(ii) For $\underline{w}_{J} \leq w<\bar{w}_{J}$, there exists a threshold $\hat{\pi}_{H}$, such that $w_{J}^{*}=\underline{w}_{J}$ for all $\pi_{H} \geq \hat{\pi}_{H}$, and $w_{J}^{*} \in\left(\underline{w}_{J}, \bar{w}_{J}\right)$ for all $\pi_{H}<\hat{\pi}_{H}$.

If $w_{J}^{*}=\underline{w}_{J}$, then $E U_{J}(w)$ is strictly decreasing in $w$ for $w \in\left[\underline{w}_{J}, \bar{w}_{J}\right)$.

If $w_{J}^{*}>\underline{w}_{J}$, then $E U_{J}(w)$ is strictly increasing in $w$ for $w \in\left[\underline{w}_{J}, w_{J}^{*}\right)$, and strictly decreasing in $w$ for $w \in\left(w_{J}^{*}, \bar{w}_{J}\right)$.

(iii) For $w \geq \bar{w}_{J}, E U_{J}(w)$ is constant in $w$.

Lemma 4 shows that a partner's expected utility under joint asset ownership is not necessarily monotone in wealth. This is because wealth has two opposite effects. It allows Alice and Bob in case of asymmetric outside options to improve their ex post payoffs in the bad state $\pi=\pi_{L}$. However, this concurrently compromises Alice's and Bob's incentives to invest in their relationship (see Proposition 2). Which effect dominates then depends on the importance of relation-specific investments, as reflected by the parameter $\pi_{H}$. For sufficiently high values of $\pi_{H}\left(\pi_{H} \geq \hat{\pi}_{H}\right)$, the incentive effect always dominates. In this case the expected utility $E U_{J}(w)$ is decreasing in $w$, and has its maximum at zero wealth. ${ }^{25}$ For lower values of $\pi_{H}\left(\pi_{H}<\hat{\pi}_{H}\right)$, the incentive effect does not always dominate. In the online Appendix, we show that the expected utility $E U_{J}(w)$ first increases in wealth and then decreases.

\footnotetext{
${ }^{25}$ If $\underline{w}_{J}>0, E U_{J}(w)$ reaches its maximum throughout the range $\left[0, \underline{w}_{J}\right]$.
} 

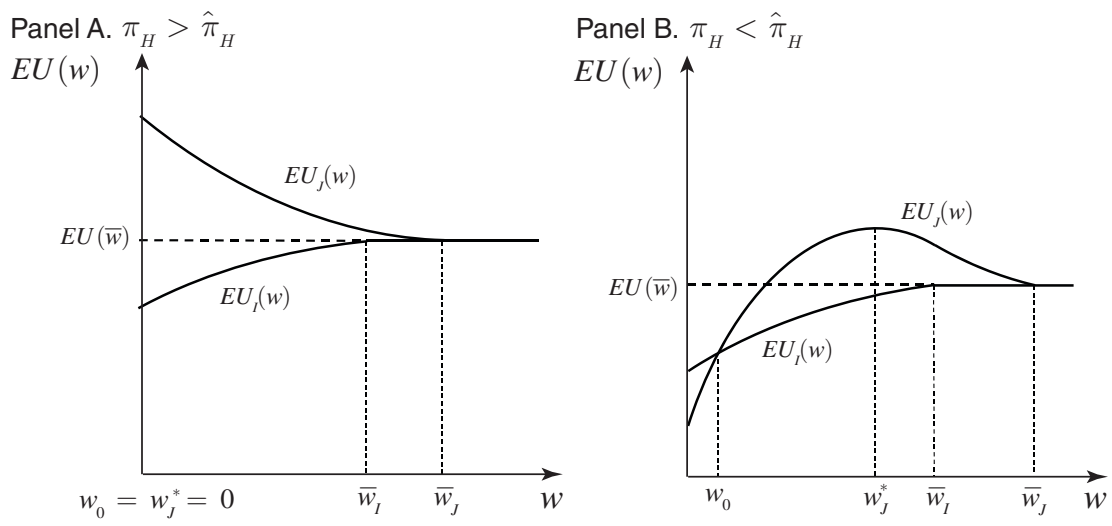

Figure 5. Wealth and Expected Utilities Under Individual and JoInt AsSET OWNership

Whereas Proposition 2 focused on specific investments, our next proposition focuses on optimal asset ownership. Specifically we derive a condition for when Alice and Bob prefer joint to individual asset ownership at date 0. For parsimony, we define $\bar{w} \equiv \max \left\{\bar{w}_{I}, \bar{w}_{J}\right\}$.

PROPOSITION 3: There always exists a critical wealth level $w_{0}$, with $w_{0} \in\left[0, w_{J}^{*}\right]$, such that for all $w \in\left(w_{0}, \bar{w}\right)$, the partners strictly prefer joint over individual asset ownership.

Figure 5 compares the expected utility levels under individual versus joint asset ownership. If Alice and Bob have sufficient wealth $(w \geq \bar{w})$, they can eliminate all ex post inefficiencies in case of asymmetric outside options. The specific ownership structure is then irrelevant (i.e., $E U_{I}(w)=E U_{J}(w)$ for $w \geq \bar{w}$ ). For $w<\bar{w}$, however, there always exists a region where joint asset ownership is preferred to individual asset ownership. This region extends all the way down to $w_{0}$. In some cases we have $w_{0}=0$, so that joint asset ownership is optimal for all levels of wealth; see the left graph of Figure 5, where $\pi_{H} \leq \hat{\pi}_{H}$. In other cases we have $w_{0}>0$, so that joint asset ownership is only optimal for intermediate levels of wealth; see the right graph of Figure 5 where $\pi_{H}>\hat{\pi}_{H}$. All this implies that the two partners, Alice and Bob, only choose individual asset ownership at date 0 when (i) relation-specific investments are not very important for their partnership $\left(\pi_{H} \leq \hat{\pi}_{H}\right)$, and (ii) they have little or no initial wealth $\left(w \leq w_{0}\right)$. Otherwise they always have a (weak) preference for joint asset ownership.

\section{Changing Available Transfer Amounts}

The analysis so far assumes that the two partners use their entire wealth for transfer payments to mitigate any ex post inefficiencies. We now ask whether and how the partners would change the amount they can use for such transfers. 
A simple inspection of Figure 5 reveals that the highest utility across all levels of $w$ is always associated with joint ownership at $w=w_{J}^{*}$. Formally, the maximum of the expected utilities, $E U^{\max }=\max \left\{E U_{I}(w), E U_{J}(w)\right\}$, is always reached at $E U_{J}\left(w_{J}^{*}\right)$. Consequently, if the partners could freely choose the amount $t$ they can use for ex post transfer payments, then they would always choose $t^{*}=w_{J}^{*}$ and agree on joint ownership. In the left panel $\left(\pi_{H} \geq \hat{\pi}_{H}\right)$, the optimal transfer is given by $t^{*}=w_{J}^{*}=0$, and in the right panel $\left(\pi_{H}<\hat{\pi}_{H}\right)$, we have $t^{*}=w_{J}^{*}>0$. We note that $t^{*}=w_{J}^{*}<\bar{w}$, so that using maximal amounts for transfer payments does not generate the highest expected utilities. This is because large potential transfers dampen incentives for specific investments.

Is it possible for partners to change the amount they can use for ex post transfers? Consider first the case of too little wealth, i.e., the case where $w<w_{J}^{*}$. The question is whether it is optimal for the partners to relax the binding wealth constraint by raising financing from an outside investor. In the online Appendix, we formally show that using outside financing does not improve the partners' expected utilities. This is because investors require a return on their investment, and this return comes from future profits. Giving outside investors, who are not part of the production process, a stake in future profits generates a distortion that is very similar to the distortion that their money is supposed to solve.

Under joint asset ownership, outside capital could be used to buy out a partner. However, the outside investor would need to get at least the same stake in the new partnership as the stake received by the original partner that is being bought out. This essentially means replacing one nonproductive partner with another. Under individual asset ownership, outside capital could be used to either retain a partner with a better outside option (in case of leaving), or implement a more efficient allocation of equity (in case of staying with renegotiation). Again, outside investors would require a stake in the partnership even though they do not contribute to the production process. This compromises the effort incentives of the productive partners, and leads to lower expected payoffs. We conclude that using outside capital to address ex post inefficiencies is not a substitute for wealth. Put differently, what is binding in our model is not merely a financing constraint, but truly a wealth constraint.

Next, we consider the case of too much wealth, so that $w>w_{J}^{*}$. Here, the question is whether wealthy partners can commit themselves ex ante to not use their entire wealth for transfers ex post. In principle, the two partners would like to commit to never dissolve an asymmetric partnership by having one partner buying out the other. ${ }^{26}$ At the same time, they want to retain the flexibility to dissolve a poor but symmetric partnership by mutual consent, without making transfer payments. At first glance it seems that the two parties can simply write a contract that stipulates that they can never make transfer payments to dissolve the partnership; if they do, then they have to pay a large penalty.

The problem is that such a contract is not renegotiation proof. If the penalty is to be paid from one partner to the other, then it can simply be waived as part of a new

\footnotetext{
${ }^{26}$ Strictly speaking, this applies only to the case of $t^{*}=w_{J}^{*}=0$, which we will focus on here. In the case of $t^{*}=w_{J}^{*}>0$, the two partners would like to commit never to pay more than $t^{*}$ to dissolve an asymmetric partnership. The analysis is very similar.
} 
agreement to dissolve the partnership. Even if the penalty goes to a third party, there can be renegotiation, where the third party (which does not expect to ever collect the penalty) waives the penalty in exchange for some modest settlement. The only way to get commitment is if there exists some third party that can credibly stay away from any renegotiation. However, it is unclear who that third party would be in reality. Simply assuming its existence is essentially the same as directly assuming commitment. In the absence of such commitment, wealthy partners cannot stop themselves from using their wealth to resolve ex post inefficiencies. Overall we conclude that credibly limiting the amount that partners can use for ex post transfers, remains problematic.

\section{Asymmetric Partners}

In our base model, we focused on two symmetric partners. Naturally one may ask whether our key trade-off between displacement and retention externalities remains intact when allowing for asymmetric partners. We focus on two sources of asymmetry: asymmetric wealth and asymmetric outside options.

Suppose the two partners have different initial wealth levels. For example, one of the partners may be a wealth-constrained entrepreneur, the other an established corporation with large cash reserves. For simplicity suppose that Alice is fully wealth constrained but Bob faces no such constraints. Consider individual asset ownership with a high inside prospect $\left(\pi_{H}\right)$. If only Alice finds an outside partner, she may want to leave. This causes a displacement externality. Now if Bob has wealth, he can make a transfer payment that convinces Alice to stay, making both parties better off. Unfortunately this solution only works in one of the two asymmetric scenarios. If only Bob finds an outside partner, he may want to leave. Alice does not have the wealth to retain Bob, and thus the displacement externality arises again in equilibrium. A similar argument applies to joint asset ownership with a low inside prospect $\left(\pi_{L}\right)$. If only Bob finds an outside partner, he normally is affected by the retention externality. If Bob has wealth, he can make a transfer payment to buy out Alice. However, if only Alice finds an outside partner, she cannot buy herself free, and the retention externality arises again in equilibrium. Overall we see that with asymmetrically wealthy partners the same inefficiencies occur, only less frequently. All that is needed for our key model insights is that at least one of the partners has insufficient wealth to completely eliminate potential displacement and retention externalities.

It remains to discuss how asymmetric expectations about their outside options affect the partners' assets ownership decisions. For this we use a simplified version of our model without specific investments, where Alice and Bob each get a utility $\pi / 2$ when staying together and $\sigma / 2$ when matching with alternative partners. We also assume that Alice will find an alternative partner, Charles, with probability $q_{A}$, while Bob will find Dora with probability $q_{B}\left(\neq q_{A}\right)$.

In the online Appendix, we show that Alice prefers joint asset ownership if

$$
q_{A}<\hat{q}_{A}=\left[\left(\frac{1-q_{B}}{q_{B}}\right)\left(\frac{\sigma-\pi}{\pi}\right)+1\right]^{-1} .
$$


Panel A. $\pi<\sigma / 2$

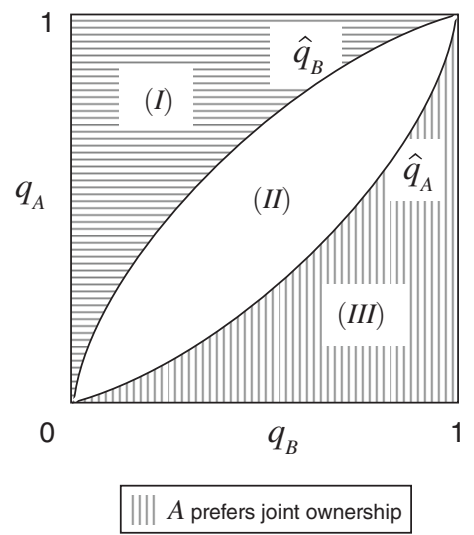

Panel B. $\pi>\sigma / 2$

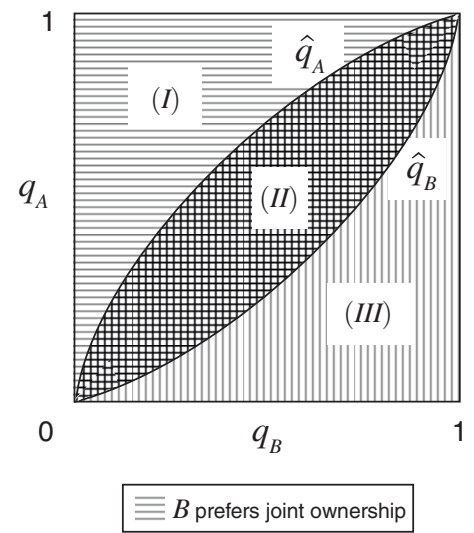

Figure 6. Preferences with Ex Ante Asymmetric Outside Options

Likewise, Bob favors joint ownership if $q_{B}<\hat{q}_{B}$, where $\hat{q}_{B}$ is symmetric to $\hat{q}_{A}$. The threshold $\hat{q}_{A}\left(\hat{q}_{B}\right)$ is increasing and convex in $q_{B}\left(q_{A}\right)$ when $\pi<\sigma / 2$. When $\pi>\sigma / 2$, it is increasing and concave in $q_{B}\left(q_{A}\right)$.

Figure 6 illustrates Alice's and Bob's preferences for joint asset ownership, for different values of $q_{A}(y$-axis $)$ and $q_{B}$ (x-axis). Consider first the left graph where $\pi<\sigma / 2$, i.e., where leaving is efficient from a joint perspective. In region $(I I I)$, Alice is sufficiently unlikely to find an alternative partner, and therefore prefers the protection of joint asset ownership $\left(q_{A}<\hat{q}_{A}\right)$. Likewise, Bob only prefers joint asset ownership in region $(I)\left(q_{B}<\hat{q}_{B}\right)$. We can see that for $\pi<\sigma / 2$, the two partners never agree on sharing control rights. Thus, individual asset ownership is the equilibrium outcome for all $q_{A}, q_{B} \in(0,1)$.

The right graph illustrates Alice's and Bob's preferences when $\pi>\sigma / 2$, i.e., when staying together maximizes their joint surplus. Again, each partner prefers joint asset ownership only when he is sufficiently unlikely to find an alternative match. For Alice this happens in regions $(I I)$ and $(I I I)$, for Bob in regions $(I)$ and (II). In region (II), Alice and Bob both prefer to share control over their assets. Joint asset ownership therefore requires that the two partners are not too dissimilar in terms of their outside prospects.

\section{Empirical Predictions}

Our model generates several important empirical predictions. Some of these echo established theories, others cover new ground. Some of them are already supported by empirical evidence, others call for new investigations. All of our empirical predictions follow a logical path from exogenous parameters (asset specificity and alternative partner matches), to the choice of ownership structure (here we focus on integration versus independence), to the level of specific investments, to the dynamic stability of partner matches. We organize our most important empirical implications in terms of four central predictions. For each of them we then delve 
into their measurement challenges, their existing empirical support, and potential avenues for further empirical testing. The main four empirical predictions are:

- higher asset specificity increases the likelihood of integration,

- greater alternative partner potential decreases the likelihood of integration,

- integration encourages more specific investments; and

- integration leads to greater partner stability.

The first hypothesis is based on the model results concerning the inside prospect $\pi$. This hypothesis is clearly not new; it echoes one of the fundamental tenets of Williamson's transaction cost theory. The models of GHM famously challenge Williamson's arguments about asset specificity, and instead emphasize the importance of specific investments (discussed under our third hypothesis). Our contribution here is to provide a new formalization of Williamson's old hypothesis. By and large, the accumulated empirical evidence supports Williamson's prediction. The seminal work of Joskow (1985) on the coal-burning electricity industry is an early example. The surveys of Lafontaine and Slade (2007, 2013) and Joskow (2010) discuss a much larger body of work. The empirical tests come from a variety of industries, and use as independent variables a variety of asset specificity measures, such as geographic proximity, or the strength of vertical trading relationships. In this literature the main dependent variable is the endogenous choice of ownership structure. Empirically this can be looked at through the integration lens of whether there is some form of joint control, be it vertical integration, cross-holdings, joint ventures, or strategic investments. From the perspective of a focal firm, this can also be analyzed in terms of make-versus-buy decisions. Yet another perspective is the contractual lens of comparing long-term versus short-term contracts.

The second hypothesis addresses the role of potential alternative matches. In the model this corresponds to the value of the outside prospect $\sigma$ and the probability of an alternative match $q$. Our dynamic modelling of the possibility of finding better outside partners generates a novel prediction that is different from both Williamson and GHM. In GHM, potential outside partners always remain inferior, which is why GHM never discover our core trade-off between displacement and retention externalities. Williamson does look at ex post frictions, but argues that greater uncertainty encourages integration. We introduce a different type of dynamic uncertainty, about the quality of the partner match. This leads us to the opposite prediction, namely that partner risk discourages integration. Measuring the potential for alternative partner matches is empirically challenging. Conceptually there is a spectrum from entrepreneurial to established business opportunities. On the entrepreneurial end, opportunities are not yet well defined, and there is a high likelihood of finding alternative asset constellations that generate higher value. On the established end, business models are well honed, and there is a clearer understanding of how different assets can be combined to maximize economic returns. See Gans, Stern, and Wu (2016) for a useful discussion. Ideally one would empirically capture this spectrum with measures of technological and business model maturity; industry and firm age are cruder proxies. Recent work by Frésard, Hoberg, and Phillips (2015) provides some indirect evidence in support of our second empirical prediction. Using a text-based 
analysis to measure vertical relationships, they find a positive relationship between firm age and vertical integration. ${ }^{27}$

Our third prediction differs from the predictions of the GHM models. While specific investments play a central role in their theories, their predictions are ambiguous and depend on model details, such as the cross-elasticities of the investment functions. By contrast our model generates an unambiguous prediction that integration leads to higher levels of specific investments. Measuring specific investments remains challenging (which is in line with the observation that most theories treat them as non-contractible). Empirically one may look at codependent technology choices (e.g., the adoption of technology platforms), or codependent investment decisions (e.g., interrelated R\&D expenditures). The seminal work by Monteverde and Teece (1982) on the US automobile industry, or the empirical analysis of franchise contracts by Brickley, Misra, and Van Horn (2006), support our main prediction that integration is associated with more specific investments.

Our final prediction concerns partner stability. This is where our theory departs from much of the prior literature, and explicitly calls for a dynamic examination of firm boundaries. As noted above, the assumptions of GHM exclude the possibility of switching a partner ex post. In Williamson's transaction cost theories, ex post adjustments play a large role, but the issue of partner switching does not feature prominently. To test our fourth prediction one has to go beyond the more traditional approach of doing a cross-sectional analysis; our concept of partner stability explicitly requires looking at time-series evidence. The recent work of Atalay, Hortaçsu, and Syverson (2014) goes in that direction by looking at dynamic responses to ownership changes. A more direct empirical test of our hypothesis would require looking at the incidence of ownership boundary changes, not only in terms of merger and acquisitions, but also in terms of divestments and spin-outs. In addition one could also look at the stability of trading relationships, such as the frequency of switching suppliers, or even the frequency of changing partners across successive strategic alliances.

\section{Conclusion}

This paper develops a dynamic theory of optimal firm boundaries based on partner uncertainty. The model identifies a fundamental trade-off between two ex post inefficiencies. Under non-integration (i.e., individual asset ownership) there can be a displacement externality, where a partner may leave even though the benefit is worth less than the loss to the displaced partner. Under integration (i.e., joint asset ownership) there can be a retention externality, where one partner may hold on to the other, even though the benefit to the departing partner would exceed the loss to the remaining partner. Moreover, we show that wealth has two distinct effects. Ex post, wealth mitigates the displacement and retention externalities. Ex ante, however,

\footnotetext{
${ }^{27}$ Our second prediction is also in tune with popular writings about entrepreneurial strategy. The so-called "lean start-up" movement (see Ries 2011 and Blank 2013) emphasizes the importance of experimentation before making longer-term commitments, and the importance of strategic pivots, where entrepreneurial companies retain the flexibility to repeatedly change their business models before committing to a specific strategy.
} 
wealth reduces incentives for specific investments. We also find that wealthy owners always want to commit ex ante to limiting ex post transfer payments.

Our analysis suggests avenues for further theoretical work. We focused on team incentives and wealth constraints as source of ex post inefficiencies; but there may be other sources of inefficiencies, such as asymmetric information (Aghion et al. 2012). Future research may therefore examine how alternative ex post inefficiencies affect the dynamic properties of firm boundaries. In our model, the arrival of superior partners is exogenous. Another interesting extension would be to consider the strategies that firms choose to identify alternative partners. Finally, we chose the simplest possible dynamic specification where partners have at most one opportunity to switch. A worthwhile future research agenda is to extend the model to an infinite horizon. This would allow for a more comprehensive analysis of how asset ownership affects the timing and frequency of partner changes. Overall we believe that looking at the dynamics of asset ownership over time constitutes a new and promising direction for future research.

\section{REFERENCES}

Aghion, Philippe, and Patrick Bolton. 1987. "Contracts as a Barrier to Entry." American Economic Review 77 (3): 388-401.

Aghion, Philippe, and Patrick Bolton. 1992. "An Incomplete Contracts Approach to Financial Contracting." Review of Economic Studies 59 (3): 473-94.

- Aghion, Philippe, Drew Fudenberg, Richard Holden, Takashi Kunimoto, and Olivier Tercieux. 2012. "Subgame-Perfect Implementation under Information Perturbations." Quarterly Journal of Economics 127 (4): 1843-81.

-Atalay, Enghin, Ali Hortaçsu, and Chad Syverson. 2014. "Vertical Integration and Input Flows." American Economic Review 104 (4): 1120-48.

- Bajari, Patrick, and Steven Tadelis. 2001. "Incentives versus transaction costs: A theory of procurement contracts." RAND Journal of Economics 32 (3): 387-407.

- Binmore, Ken, Ariel Rubinstein, and Asher Wolinsky. 1986. "The Nash bargaining solution in economic modelling." RAND Journal of Economics 17 (2): 176-88.

Blank, Steve. 2013. "Why the Lean Start-Up Changes Everything." Harvard Business Review 91 (5): 63-72.

Blonski, Matthias, and Giancarlo Spagnolo. 2003. "Relational Contracts and Property Rights." Center for Economic and Policy Research (CEPR) Discussion Paper 3460.

Bolton, Patrick, and Michael D. Whinston. 1993. "Incomplete Contracts, Vertical Integration, and Supply Assurance." Review of Economic Studies 60 (1): 121-48.

-Brickley, James A., Sanjog Misra, and R. Lawrence Van Horn. 2006. "Contract Duration: Evidence from Franchising." Journal of Law and Economics 49 (1): 173-96.

- Brien, Michael J., Lee A. Lillard, and Steven Stern. 2006. "Cohabitation, Marriage, and Divorce in a Model of Match Quality." International Economic Review 47 (2): 451-94.

- Cai, Hongbin. 2003. "A theory of joint asset ownership." RAND Journal of Economics 34 (1): 63-77.

Casas-Arce, Pablo, and Thomas Kittsteiner. 2011. "Opportunism and Incomplete Contracts." http:// www.mikrooekonomie.rwth-aachen.de/workingpaper/Opportunism_and_Incomplete_Contracts. pdf.

-Cramton, Peter, Robert Gibbons, and Paul Klemperer. 1987. "Dissolving a Partnership Efficiently." Econometrica 55 (3): 615-32.

de Fontenay, Catherine C., Joshua S. Gans, and Vivienne Groves. 2010. "Exclusivity, competition and the irrelevance of internal investment." International Journal of Industrial Organization 28 (4): 336-40.

de Frutos, María-Angeles, and Thomas Kittsteiner. 2008. "Efficient partnership dissolution under buy-sell clauses." RAND Journal of Economics 39 (1): 184-98.

-Franco Mitchell, April, Matthew Mitchell, and Galina Vereshchagina. 2011. "Incentives and the structure of teams." Journal of Economic Theory 146 (6): 2307-32. 
Frésard, Laurent, Gerard Hoberg, and Gordon Phillips. 2015. "Innovation Activities and the Incentives for Vertical Acquisitions and Integration." http://faculty.tuck.dartmouth.edu/images/uploads/ faculty/gordon-phillips/vertical_integration.pdf.

Friedberg, Leora. 1998. "Did Unilateral Divorce Raise Divorce Rates? Evidence from Panel Data." American Economic Review 88 (3): 608-27.

Gans, Joshua S. 2005. "Markets for ownership." RAND Journal of Economics 36 (2): 433-45.

Gans, Joshua S., and Scott Stern. 2003. "The product market and the market for 'ideas': Commercialization strategies for technology entrepreneurs." Research Policy 32 (2): 333-50.

Gans, Joshua, Scott Stern, and Jane Wu. 2016. "The Foundations of Entrepreneurial Strategy." http:// web.business.queensu.ca/faculty/jdebettignies/Docs/GansEtAl16.pdf.

Gibbons, Robert. 2005. "Four formal(izable) theories of the firm?" Journal of Economic Behavior and Organization 58 (2): 200-245.

Grossman, Sanford J., and Oliver D. Hart. 1986. "The Costs and Benefits of Ownership: A Theory of Vertical and Lateral Integration." Journal of Political Economy 94 (4): 691-719.

Grossman, Sanford J., and Oliver Hart. 1987. "Vertical Integration and the Distribution of Property Rights." In Economic Policy in Theory and Practice, edited by Assaf Razin and Efraim Sadka, 504-46. New York: Palgrave Macmillan.

-Halonen, Maija. 2002. "Reputation and the Allocation of Ownership." Economic Journal 112 (481): 539-58.

Hart, Oliver. 1995. Firms, Contracts, and Financial Structure. Oxford: Clarendon Press.

-Hart, Oliver. 2009. "Hold-up, Asset Ownership, and Reference Points." Quarterly Journal of Economics 124 (1): 267-300.

-Hart, Oliver, and Bengt Holmström. 2010. "A Theory of Firm Scope.” Quarterly Journal of Economics 125 (2): 483-513.

-Hart, Oliver, and John Moore. 1990. "Property Rights and the Nature of the Firm." Journal of Political Economy 98 (6): 1119-58.

-Hart, Sergiu. 2004. "A Comparison of Non-transferable Utility Values." Theory and Decision 56 (1-2): 35-46.

-Hart, Sergiu, and Andreu Mas-Colell. 1996. "Bargaining and Value." Econometrica 64 (2): $357-80$.

- Hellmann, Thomas, and Enrico Perotti. 2011. "The Circulation of Ideas in Firms and Markets." Management Science 57 (10): 1813-26.

-Hellmann, Thomas, and Veikko Thiele. 2015. "Contracting among Founders." Journal of Law, Economics, and Organization 31 (3): 629-61.

- Holmström, Bengt. 1982. "Moral hazard in teams." Bell Journal of Economics 13 (2): 324-40.

- Jing, Ran, and Ralph A. Winter. 2014. "Exclusionary Contracts." Journal of Law, Economics, and Organization 30 (4): 833-67.

Joskow, Paul L. 1985. "Vertical Integration and Long-Term Contracts: The Case of Coal-Burning Electric Generating Plants." Journal of Law, Economics, and Organization 1 (1): 33-80.

- Joskow, Paul L. 2010. "Vertical Integratio." Antitrust Bulletin 55 (3): 545-86.

- Lafontaine, Francine, and Margaret Slade. 2007. "Vertical Integration and Firm Boundaries: The Evidence." Journal of Economic Literature 45 (3): 629-85.

Lafontaine, Francine, and Margaret E. Slade. 2013. "Inter-Firm Contracts." In Handbook of Organizational Economics, edited by Robert Gibbons and John Roberts, 958-1013. Princeton: Princeton University Press.

Maschler, Michael, and Guillermo Owen. 1992. "The Consistent Shapley Value for Games without Side Payments." In Rational Interaction: Essays in Honor of John C. Harsanyi, edited by Reinhard Selten, 5-12. New York: Springer-Verlag.

Matouschek, Niko. 2004. "Ex Post Inefficiencies in a Property Rights Theory of the Firm.” Journal of Law, Economics, and Organization 20 (1): 125-47.

-Matouschek, Niko, and Imran Rasul. 2008. "The Economics of the Marriage Contract: Theories and Evidence." Journal of Law and Economics 51 (1): 59-110.

-McAfee, R. Preston. 1992. "Amicable divorce: Dissolving a partnership with simple mechanisms." Journal of Economic Theory 56 (2): 266-93.

Monteverde, Kirk, and David J. Teece. 1982. "Supplier switching costs and vertical integration in the automobile industry." Bell Journal of Economics 13 (1): 206-13.

-Nöldeke, Georg, and Klaus M. Schmidt. 1998. "Sequential investments and options to own." RAND Journal of Economics 29 (4): 633-53.

Peters, H. Elizabeth. 1986. "Marriage and Divorce: Informational Constraints and Private Contracting." American Economic Review 76 (3): 437-54. 
-Peters, Michael. 2007. “The pre-marital investment game.” Journal of Economic Theory 137 (1): 186-213.

-Peters, Michael, and Aloysius Siow. 2002. "Competing Premarital Investments." Journal of Political Economy 110 (3): 592-608.

-Prat, Andrea. 2002. "Should a team be homogeneous?" European Economic Review 46 (7): 1187-1207.

Ries, Eric. 2011. The Lean Startup: How Today's Entrepreneurs Use Continuous Innovation to Create Radically Successful Businesses. New York: Crown Publishing.

-Segal, Ilya R., and Michael D. Whinston. 2000. "Exclusive contracts and protection of investments." RAND Journal of Economics 31 (4): 603-33.

Segal, Ilya, and Michael D. Whinston. 2013. "Property Rights.” In Handbook of Organizational Economics, edited by Robert Gibbons and John Roberts, 100-158. Princeton: Princeton University Press.

Tadelis, Steven. 2002. "Complexity, Flexibility, and the Make-or-Buy Decision.” American Economic Review 92 (2): 433-37.

-Whinston, Michael D. 2003. "On the Transaction Cost Determinants of Vertical Integration.” Journal of Law, Economics, and Organization 19 (1): 1-23.

-Wickelgren, Abraham L. 2009. "Why Divorce Laws Matter: Incentives for Noncontractible Marital Investments under Unilateral and Consent Divorce." Journal of Law, Economics, and Organization 25 (1): 80-106.

Williamson, Oliver E. 1975. Markets and Hierarchies: Analysis and Antitrust Implications. New York: Free Press.

Williamson, Oliver E. 1985. The Economic Institutions of Capitalism. New York: Free Press.

-Wolfers, Justin. 2006. "Did Unilateral Divorce Laws Raise Divorce Rates? A Reconciliation and New Results." American Economic Review 96 (5): 1802-20. 